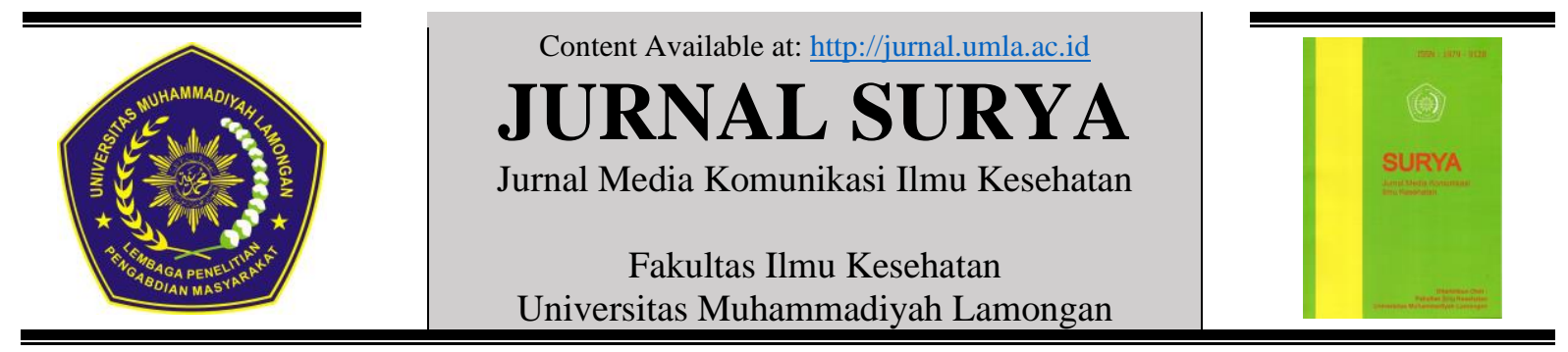

\title{
Identifikasi Mutu Pelayanan Perawatan Dan Tingkat Kepuasan Pasien Di Puskesmas Kecamatan Lamongan
}

Muhamad Ganda Saputra ${ }^{1}$, Ajeng Putri Mahfiroh ${ }^{2}$, Faizatul Ummah ${ }^{3}$, Nahardian Vica Rahmawati $^{4}$

${ }^{1}$ Staf Pengajar Prodi 1 Administrasi Rumah Sakit Universitas Muhammadiyah Lamongan

${ }^{2}$ Mahasiswa Prodi S1 Administrasi Rumah Sakit Universitas Muhammadiyah Lamongan

${ }^{3}$ Staf Pengajar Prodi 1 Administrasi Rumah Sakit Universitas Muhammadiyah Lamongan

${ }^{4}$ Staf Pengajar Prodi S1 Administrasi Rumah Sakit Universitas Muhammadiyah Lamongan

\section{ARTIKEL INFO}

\section{Article History:}

SM at 12-02-2020

$R V$ at $15-05-2020$

$P B$ at 25-06-2020

\section{Kata Kunci:}

Mutu Pelayanan

Puskesmas

Kepuasan

\section{Korespondensi Penulis:}

muhamadgandasaputra77@gmail.com 085645040345

\begin{abstract}
ABSTRAK
Background: Pembangunan nasional dibidang kesehatan diarahkan untuk meningkatkan derajat kesehatan serta mutu kehidupan melalui pemerataan pelayanan kesehatan untuk menjangkau seluruh lapisan masyarakat.
\end{abstract}

Objective : Banyaknya pasien yang belum puas dengan pelayanan yang diberikan Puskesmas Lamongan. Tujuan penelitian adalah mengetahui gambaran mutu pelayanan perawatan dan tingkat kepuasan pasien.

Design: Desain penelitian ini adalah Deskriptif, sebagai populasi adalah seluruh pasien yang berobat ke Puskesmas Lamongan tanggal 04 sampai dengan 30 Desember 2019. Pengambilan sampel dengan tehnik non probability sampling yakni Consecutive Sampling dengan sampel yang diambil 46 responden.

Data Sources : Data diambil menggunakan kuesioner, data terkumpul dilakukan penyuntingan data dan koding selanjutnya dikonfirmasikan dalam bentuk prosentase dan narasi.

Result : Hasil penelitian menunjukkan $87,0 \%$ atau hampir seluruh responden puas dengan pelayanan petugas, sarana prasarana serta prosedur dan $73,9 \%$ atau lebih dari sebagian responden puas dengan ketanggapan, ketepatan waktu, prosedur, sarana prasarana serta jumlah petugas di Puskesmas Lamongan.

Coclusions : Dapat disimpulkan bahwa hampir seluruh responden puas dengan pelayanan petugas, sarana prasarana serta prosedur dan lebih dari sebagian responden puas dengan ketanggapan, ketepatan waktu, prosedur, sarana prasarana serta jumlah petugas di Puskesmas Lamongan. Diharapkan petugas kesehatan dapat memberikan pelayanan yang optimal. 
PENDAHULUAN

Pembangunan nasional dibidang kesehatan diarahkan untuk meningkatkan derajat kesehatan masyarakat, meningkatkan mutu sumber daya manusia serta mutu kehidupan manusia melalui kemudahan dan pemerataan pelayanan kesehatan untuk menjangkau seluruh lapisan masyarakat. Tercapainya keadaan ini akan ditandai dengan meningkatnya umur harapan hidup, menurunnya angka kematian bayi, anak dan ibu melahirkan, meningkatnya kesejahteraan keluarga, meningkatnya produktivitas kerja dan meningkatnya perilaku hidup sehat di lingkungan masyarakat. Untuk tercapainya tujuan tersebut maka kebijakan kesehatan diarahkan untuk pengembangan upaya, tenaga maupun sarana sehingga memadai dan mampu berperanan dalam meningkatkan derajat kesehatan masyarakat.

Derajat kesehatan yang optimal dapat dicapai dengan peningkatan mutu lingkungan dan perubahan tingkah laku masyarakat serta pelayanan kesehatan yang merata, menyeluruh dan terpadu yang memegang peranan yang sangat penting dalam pembangunan nasional (Kemenkes RI, 2018).

Kebutuhan dan tuntutan masyarakat akan mutu pelayanan kesehatan semakin meningkat sejalan dengan peningkatan pengetahuan dan kemampuan masyarakat maupun perkembangan ilmu pengetahuan dan teknologi kesehatan.

Perubahan dan perkembangan ilmu pengetahuan dan teknologi kesehatan ini sangat mempengaruhi orientasi pelayanan kesehatan dari pelayanan yang bersifat kuratif dan rehabilitatif bagi perorangan, menjadi yang lebih bersifat promotif dan preventif bagi masyarakat luas.

Pelayanan asuhan keperawatan yang optimal akan terus sebagai suatu tuntutan bagi organisasi pelayanan kesehatan. Saat ini adanya suatu keinginan untuk merubah sistem pemberian pelayanan kesehatan ke sistem desentralisasi. Dengan meningkatnya pendidikan bagi perawat, diharapkan dapat memberikan arah terhadap pelayanan keperawatan (Nursalam, 2016).

Dari data yang telah diperoleh pada tahun 2018 di Puskesmas Kecamatan Lamongan, jumlah kunjungan pasien pada tribulan pertama sebanyak 9220 kunjungan, pada tribulan kedua sebanyak 8964 kunjungan, pada tribulan ketiga sebanyak 8846 kunjungan dan pada tribulan keempat sebanyak 7526 kunjungan. Dari data di atas dapat dilihat bahwa terdapat penurunan yang berturut- turut pada jumlah kunjungan pasien di Puskesmas Kecamatan Lamongan. Kemudian dari survey awal yang dilakukan peneliti pada pasien yang berobat ke Puskesmas Kecamatan Lamongan dengan 10 responden untuk mutu pelayanan didapatkan 6 responden mengatakan mutu pelayanan tentang ketanggapan petugas, ketepatan waktu, prosedur, sarana dan prasarana serta jumlah petugas kurang dan 4 responden mengatakan mutu pelayanan tentang ketanggapan petugas, ketepatan waktu, prosedur, sarana dan prasarana serta jumlah petugas baik. Sedangkan untuk kepuasan pasien didapatkan 3 responden dengan tingkat kepuasan tinggi terhadap pelayanan petugas, posedur, sarana dan prasarana serta 7 responden dengan tingkat kepuasan rendah terhadap pelayanan petugas, posedur, sarana dan prasarana.

Banyaknya pasien yang belum puas dengan terhadap pelayanan yang diberikan di Puskesmas Kecamatan Lamongan, yang mana dapat diidentifikasi beberapa faktor yang mempengaruhi diantaranya adalah mutu pelayanan, petugas kesehatan, prosedur dan sarana/ prasarana kesehatan.

Mutu pelayanan adalah suatu keputusan yang berhubungan dengan proses pelayanan yang berdasarkan tingkat dimana pelayanan memberikan kontribusi terhadap nilai out cames (Wijono. Dj, 2012). Salah satu indikator mutu pelayanan adalah tingkat kepuasan klien sebagai pengguna jasa. Kepuasan klien dalam menjalani perawatan pada kenyataannya sering diabaikan sehingga menumbuhkan rasa tidak percaya terhadap petugas kesehatan kemungkinan hal ini akan memberikan dampak negatif terhadap tingkat kepuasan klien di puskesmas yang bersangkutan.

Petugas kesehatan adalah setiap orang yang mengabdikan diri dalam bidang kesehatan serta memiliki pengetahuan dan atau ketrampilan melalui pendidikan di bidang kesehatan yang untuk jenis tertentu memerlukan kewenangan untuk melakukan upaya kesehatan (Wijono. Dj, 2012). Selalu diupayakan agar petugas kesehatan 
memberikan pelayanan dengan sikap ramah dan sopan serta berupaya meningkatkan kinerja pelayanan secara optimal dengan kemampuan pelayanan yang tersedia dalam jumlah dan jenis yang cukup.

Prosedur adalah suatu seni atau rangkaian langkah- langkah yang saling berhubungan atau pekerjaan- pekerjaan yang dinyatakan secara kronologis dengan maksud untuk mencapai maksud tertentu yang harus diikuti (Wijono. Dj, 2012). Prosedur benarbenar merupakan petunjuk- petunjuk untuk tindakan dan bukan untuk cara berfikir. Prosedur memberikan detail- detail tindakan, dengan prosedur sesuatu aktivitas tertentu harus dilaksanakan. Esensinya adalah rentetan tindakan yang diatur secara kronologi/ berurutan.

Sarana kesehatan adalah tempat yang diguanakan untuk menyelenggarakan upaya kesehatan yang meliputi balai pengobatan, Puskesmas, Rumah Sakit, praktek dokter, praktek bidan, apotek, laboratorium dan sarana kesehatan lainnya (Wijono. Dj, 2012).

Kurang atau tidak bermutunya layanan kesehatan puskesmas bukan kesalahan puskesmas, tetapi sistem layanan kesehatan puskesmas itu sendiri yang menjadikannya kurang atau tidak bermutu (Pohan, 2012).

Sehingga dari masalah diatas menimbulkan suatu dampak yang mempengaruhi jumlah kunjungan pasien diantaranya sistem pelayanan perawatan yang kurang bermutu.

Disini peran petugas kesehatan sangat dibutuhkan dalam upaya meningkatkan mutu pelayanan perawatan. Selalu diupayakan agar petugas kesehatan memberikan pelayanan perawatan dengan berupaya meningkatkan kinerja pelayanan secara optimal.

\section{METODE}

Jenis desain penelitian ini adalah deskriptif yaitu suatu metode penelitian yang dilakukan dengan tujuan utama untuk membuat gambaran atau deskripsi tentang suatu keadaan secara objektif (Notoatmodjo. $S, 2010)$. Desain dalam penelitian ini adalah memberikan gambaran terhadap mutu pelayanan perawatan dan tingkat kepuasan pasien di Puskesmas Kecamatan Lamongan.
Pada penelitian ini populasinya adalah seluruh pasien yang berobat ke Puskesmas Kecamatan Lamongan pada tanggal 04 - 30 Desember 2019. Pada penelitian ini sampel yang diambil pasien yang berobat ke Puskesmas Kecamatan Lamongan sebagai kunjungan lama pada tanggal 04 - 30 Desember 2019 dengan sample sebanyak 46 responden.

Pada penelitian ini untuk menentukan sampel yang akan diteliti dipakai teknik consecutive sampling yaitu pemilihan sampel dengan menetapkan subjek yang memenuhi kriteria penelitian dimasukkan dalam penelitian sampai kurun waktu tertentu, sehingga jumlah pasien yang diperlukan terpenuhi.

Instrumen penelitian yang digunakan dalam penelitian ini adalah kuesioner tertutup dengan model dichotomy question. yaitu suatu daftar pertanyaan yang akan ditanyakan kepada responden. Peneliti akan memberikan kuesioner sebanyak 30 pertanyaan, dimana responden tinggal memberikan jawaban ya atau tidak dengan tanda tertentu.

Setelah data terkumpul dilakukan penyuntingan data dan koding. Teknik pemberian skor pada kuesioner mutu pelayanan perawatan dan tingkat kepuasan pasien menggunakan skala ordinal dimana responden memilih jawaban ya atau tidak. Untuk pertanyaan positif bila responden memilih jawaban yang dinilai ya 1 dan tidak dinilai 0 sebaliknnya untuk pertanyaan negatif bila responden memilih jawaban ya dinilai 0 dan tidak dinilai 1. Jawaban yang sama dikelompokkan dalam satu kategori dan dihitung persennya.

Langkah berikutnya adalah mengklasifikasikan tingkat kepuasan pasien dalam tiga tingkat kategori yaitu :

Tinggi jika menjawab ya $76-100 \%$

Sedang jika menjawab ya $56-75 \%$

Rendah jika menjawab ya $\leq 55 \%$

Sedangkan untuk mutu pelayanan diklasifikasikan dalam tiga tingkat kategori yaitu :

Baik jika menjawab ya $76-100 \%$

Cukup jika menjawab ya $56-75 \%$

Kurang jika menjawab ya $\leq 55 \%$

\section{HASIL PENELITIAN}

Pengambilan data dilakukan pada pasien yang berkunjung di Puskesmas 
Kecamatan Lamongan yang memenuhi kriteria inklusi. Penyajian dimulai dari data umum tentang gambaran fisik tempat penelitian dan karakteristik responden yang meliputi umur, pendidikan dan jenis kelamin. Sedangkan data khusus disajikan berdasarkan variabel yang diukur.

1. Distribusi responden berdasarkan umur Tabel 1 Distribusi Responden Berdasarkan Umur di Puskesmas Kecamatan Lamongan Tahun 2019

\begin{tabular}{llcc}
\hline No & Umur & F & \% \\
\hline 1. & $21-30$ tahun & 7 & 15,22 \\
2. & $31-40$ tahun & 22 & 47,83 \\
3 & 41- 50 tahun & 13 & 28,26 \\
4 & $>50$ tahun & 4 & 8,69 \\
\hline \multicolumn{2}{l}{ Jumlah } & $\mathbf{4 6}$ & $\mathbf{1 0 0 , 0 0}$ \\
\hline
\end{tabular}

Dari tabel 1 menunjukkan bahwa $47,83 \%$ atau lebih dari sebagian responden berumur 31- 40 tahun dan 8,69\% atau sebagian kecil responden berumur $>50$ tahun.

2. Distribusi responden berdasarkan jenis kelamin

Tabel 2 Distribusi Responden Berdasarkan Jenis Kelamin di Puskesmas Kecamatan Lamongan Tahun 2019

\begin{tabular}{llcc}
\hline No & Jenis Kelamin & F & \% \\
\hline 1. & Laki- laki & 17 & 36,96 \\
2. & Perempuan & 29 & 63,04 \\
\hline Jumlah & $\mathbf{4 6}$ & $\mathbf{1 0 0 , 0 0}$ \\
\hline
\end{tabular}

Dari tabel 2 menunjukkan bahwa $63,04 \%$ atau lebih dari sebagian jumlah responden yang berjenis kelamin perempuan.

3. Distribusi responden berdasarkan pendidikan

Tabel 3 Distribusi Responden Berdasarkan

Pendidikan di Puskesmas Kecamatan Lamongan Tahun 2019

\begin{tabular}{llcc}
\hline No & Pendidikan & F & \% \\
\hline 1. & Tidak sekolah & 2 & 4,35 \\
2. & SD & 8 & 17,40 \\
3 & SMP & 12 & 26,08 \\
4 & SMA & 21 & 45,65 \\
5 & Perguruan Tinggi & 3 & 6,52 \\
\hline Jumlah & $\mathbf{4 6}$ & $\mathbf{1 0 0 , 0 0}$ \\
\hline
\end{tabular}

Dari tabel 3 menunjukkan bahwa $45,65 \%$ atau hampir sebagian responden berpendidikan SMU.
4. Data responden berdasarkan tingkat kepuasan pasien

Tabel 4 Distribusi Tingkat Kepuasan Pasien Tentang Pelayanan Petugas di Puskesmas Kecamatan Lamongan Tahun 2019

\begin{tabular}{|c|c|c|c|}
\hline No & Pelayanan Petugas & $\mathbf{F}$ & $\%$ \\
\hline 1. & Tinggi & 44 & 95,7 \\
\hline 2. & Sedang & 2 & 4,3 \\
\hline 3 & Rendah & 0 & 0 \\
\hline \multicolumn{2}{|c|}{ Jumlah } & 46 & 100,00 \\
\hline
\end{tabular}

95,7\% atau hampir seluruh responden puas dengan pelayanan petugas di Puskesmas Kecamatan Lamongan.

Tabel 5 Distribusi Tingkat Kepuasan Pasien Tentang Sarana dan Prasarana di Puskesmas Kecamatan Lamongan Tahun 2019

\begin{tabular}{|c|c|c|c|}
\hline No & $\begin{array}{l}\text { Sarana dan } \\
\text { Prasarana }\end{array}$ & $\mathbf{F}$ & $\%$ \\
\hline 1. & Tinggi & 17 & 37,0 \\
\hline 2. & Sedang & 27 & 58,7 \\
\hline 3 & Rendah & 2 & 4,3 \\
\hline \multicolumn{2}{|c|}{ Jumlah } & 46 & 100,00 \\
\hline
\end{tabular}

$58,7 \%$ atau lebih dari sebagian responden belum puas dengan sarana dan prasarana yang ada di Puskesmas Kecamatan Lamongan.

Tabel 6 Distribusi Tingkat Kepuasan Pasien Tentang Prosedur di Puskesmas Kecamatan Lamongan Tahun 2019

\begin{tabular}{|c|c|c|c|}
\hline No & Prosedur & $\mathbf{F}$ & $\%$ \\
\hline 1. & Tinggi & 33 & 71,7 \\
\hline 2. & Sedang & 12 & 26,1 \\
\hline 3 & Rendah & 1 & 2,2 \\
\hline \multicolumn{2}{|c|}{ Jumlah } & 46 & 100,00 \\
\hline
\end{tabular}

$71,7 \%$ atau lebih dari sebagian responden puas dengan prosedur yang dilakukan di Puskesmas Kecamatan Lamongan.

Tabel 7 Distribusi Tingkat Kepuasan Pasien di Puskesmas Kecamatan Lamongan Tahun 2019

\begin{tabular}{llcc}
\hline No & Kepuasan Pasien & F & \% \\
\hline 1. & Tinggi & 40 & 87,0 \\
2. & Sedang & 6 & 13,0 \\
3 & Rendah & 0 & 0 \\
\hline Jumlah & $\mathbf{4 6}$ & $\mathbf{1 0 0 , 0 0}$ \\
\hline
\end{tabular}


Dari tabel 7 menunjukkan bahwa $87,0 \%$ atau hampir seluruh responden puas dengan pelayanan petugas, sarana dan prasarana serta prosedur yang ada di Puskesmas Kecamatan Lamongan.

5. Data responden berdasarkan mutu pelayanan

Tabel 8 Distribusi Mutu Pelayanan Tentang Ketanggapan Petugas di Puskesmas Kecamatan Lamongan Tahun 2019

\begin{tabular}{|c|c|c|c|}
\hline No & Ketanggapan Petugas & $\mathbf{F}$ & $\%$ \\
\hline 1. & Baik & 36 & 78,3 \\
\hline 2. & Cukup & 10 & 21,7 \\
\hline 3 & Kurang & 0 & 0 \\
\hline \multicolumn{2}{|c|}{ Jumlah } & 46 & 100,00 \\
\hline
\end{tabular}

78,3\% atau hampir seluruh responden puas dengan ketanggapan petugas di Puskesmas Kecamatan Lamongan.

Tabel 9 Distribusi Mutu Pelayanan Tentang Ketepatan Waktu di Puskesmas Kecamatan Lamongan Tahun 2019

\begin{tabular}{llcc}
\hline No & Ketepatan Waktu & F & \% \\
\hline 1. & Baik & 2 & 4,3 \\
2. & Cukup & 44 & 95,7 \\
3 & Kurang & 0 & 0 \\
\hline Jumlah & $\mathbf{4 6}$ & $\mathbf{1 0 0 , 0 0}$ \\
\hline \multicolumn{2}{l}{ Dari }
\end{tabular}

Dari tabel 9 menunjukkan bahwa $95,7 \%$ atau hampir seluruh responden belum puas dengan ketepatan waktu dalam pelayanan di Puskesmas Kecamatan Lamongan.

Tabel 10 Distribusi Mutu Pelayanan Tentang Prosedur di Puskesmas Kecamatan Lamongan Tahun 2019

\begin{tabular}{|c|c|c|c|}
\hline No & Prosedur & $\mathbf{F}$ & $\%$ \\
\hline 1. & Baik & 34 & 73,9 \\
\hline 2. & Cukup & 12 & 26,1 \\
\hline 3 & Kurang & 0 & 0 \\
\hline \multicolumn{2}{|c|}{ Jumlah } & 46 & 100,00 \\
\hline
\end{tabular}

$73,9 \%$ atau lebih dari sebagian responden puas dengan prosedur yang dilakukan di Puskesmas Kecamatan Lamongan.
Tabel 11 Distribusi Mutu Pelayanan Tentang Sarana dan Prasarana di Puskesmas Kecamatan Lamongan Tahun 2019

\begin{tabular}{|c|c|c|c|}
\hline No & $\begin{array}{l}\text { Sarana dan } \\
\text { Prasarana }\end{array}$ & $\mathbf{F}$ & $\%$ \\
\hline 1. & Baik & 10 & 21,7 \\
\hline 2. & Cukup & 32 & 69,6 \\
\hline 3 & Kurang & 4 & 8,7 \\
\hline \multicolumn{2}{|c|}{ Jumlah } & 46 & 100,00 \\
\hline
\end{tabular}

69,6\% atau lebih dari sebagian responden belum puas dengan sarana dan prasarana yang ada di Puskesmas Kecamatan Lamongan.

Tabel 12 Distribusi Mutu Pelayanan Tentang Jumlah Petugas di Puskesmas Kecamatan Lamongan Tahun 2019

\begin{tabular}{llcc}
\hline No & $\begin{array}{l}\text { Sarana dan } \\
\text { Prasarana }\end{array}$ & F & \% \\
\hline 1. & Baik & 6 & 13,0 \\
2. & Cukup & 40 & 87,0 \\
3 & Kurang & 0 & 0 \\
\hline Jumlah & $\mathbf{4 6}$ & $\mathbf{1 0 0 , 0 0}$ \\
\hline
\end{tabular}

Dari tabel 12 menunjukkan bahwa

$87,0 \%$ atau hampir seluruh responden belum puas dengan jumlah petugas yang ada di Puskesmas Kecamatan Lamongan.

Tabel 13 Distribusi Mutu Pelayanan di Puskesmas Kecamatan Lamongan Tahun 2019

\begin{tabular}{|c|c|c|c|}
\hline No & $\begin{array}{l}\text { Sarana dan } \\
\text { Prasarana }\end{array}$ & $\mathbf{F}$ & $\%$ \\
\hline 1. & Baik & 34 & 73,9 \\
\hline 2. & Cukup & 12 & 26,1 \\
\hline 3 & Kurang & 0 & 0 \\
\hline \multicolumn{2}{|c|}{ Jumlah } & 46 & 100,00 \\
\hline \multicolumn{4}{|c|}{$\begin{array}{l}\text { Dari tabel } 13 \text { menunjukkan bahwa } \\
73,9 \% \text { atau lebih dari sebagian responden } \\
\text { puas dengan ketanggapan petugas, ketepatan } \\
\text { waktu, prosedur, sarana dan prasarana serta } \\
\text { jumlah petugas yang ada di Puskesmas } \\
\text { Kecamatan Lamongan. }\end{array}$} \\
\hline
\end{tabular}

\section{PEMBAHASAN}

\section{Kepuasan Pasien}

1) Kepuasan pasien berdasarkan pelayanan petugas

Dari hasil penelitian pada tabel 5 menunjukkan bahwa $95,7 \%$ atau hampir seluruh responden puas dengan pelayanan yang diberikan oleh petugas di Puskesmas 
Kecamatan Lamongan. Hal ini dikarenakan perawat kesehatan dapat dijadikan tempat bertanya untuk memecahkan permasalahan dalam bidang kesehatan, dengan adanya perawat disisi pasien, pasien merasa diperhatikan sehingga akan memupuk kepercayaan terhadap petugas kesehatan (Efendy, 2008).

Kenyataan ini menunjukkan bahwa petugas selalu diupayakan untuk memberikan pelayanan perawatan dengan berupaya meningkatkan kinerja pelayanan secara optimal.

2) Kepuasan pasien berdasarkan sarana dan prasarana

Dari hasil penelitian pada tabel 6 menunjukkan bahwa 58,7\% atau lebih dari sebagian responden belum puas dengan sarana dan prasarana yang ada di Puskesmas Kecamatan Lamongan. Hal ini dikarenakan dibagian tertentu dari puskesmas yang masih belum bekerja secara optimal misalnya sarana laboratorium yang peralatannya belum lengkap dan kursi untuk pasien yang menunggu giliran panggilan pemeriksaan belum tersedia dengan cukup.

Sarana dan prasarana kesehatan adalah tempat yang digunakan untuk menyelenggarakan upaya kesehatan yang meliputi balai pengobatan, puskesmas, Rumah Sakit, praktek dokter, praktik bidan, laboratorium dan sarana kesehatan lainnya (Wijono. Dj, 2012). Sehingga jika sarana dan prasarana yang ada di puskesmas tidak memadai, maka akan berpengaruh terhadap kepuasan pasien.

3) Kepuasan pasien berdasarkan prosedur

Dari hasil penelitian pada tabel 7 menunjukkan bahwa $71,7 \%$ atau lebih dari sebagian responden puas dengan prosedur yang dilakukan di Puskesmas Kecamatan Lamongan. Prosedur yang dilakukan di puskesmas merupakan salah satu faktor yang berpengaruh terhadap kepuasan pasien. Hal ini dikarenakan prosedur merupakan suatu seni atau rangkaian langkah - langkah yang saling berhubungan atau pekerjaan pekerjaan yang dinyatakan secara kronologis dengan maksud untuk mencapai maksud tertentu yang harus diikuti (Wijono. Dj, 2012).

Kenyataan ini menunjukkan bahwa petugas kesehatan sudah mampu dalam memberikan tindakan keperawatan yang sesuai dengan urutan atau langkah - langkah yang sudah ditentukan. Misalnya sebelum melakukan tindakan keperawatan kepada pasien petugas kesehatan terlebih dulu memberitahukan tindakan keperawatan apa yang akan dilakukan.

4) Kepuasan pasien

Dari hasil penelitian pada tabel 8 menunjukkan bahwa tingkat kepuasan responden tinggi yaitu $87,0 \%$ atau hampir seluruh responden. Kenyataan ini menunjukkan bahwa kinerja layanan kesehatan yang diterima oleh responden dapat memberikan suatu kepuasan.

Kepuasan pasien adalah suatu tingkat perasaan pasien yang timbul sebagai akibat dari kinerja layanan kesehatan yang diperolehnya setelah pasien membandingkannya dengan apa yang diharapkannya (Pohan, 2012). Hal ini menunjukkan bahwa pasien akan merasa puas dimana jika keinginan, harapan dan kebutuhan dari pasien itu terpenuhi. Dan suatu pelayanan dinilai memuaskan bila pelayanan tersebut dapat memenuhi kebutuhan dan harapan dari pasien tersebut.

\section{Mutu Pelayanan}

1) Mutu pelayanan berdasarkan ketanggapan petugas

Dari hasil penelitian pada tabel 9 menunjukkan bahwa $78,3 \%$ atau hampir seluruh responden puas dengan ketanggapan petugas di Puskesmas Kecamatan Lamongan. Dalam hal ini mutu pelayanan berarti suatu empathi, petugas tanggap akan kebutuhannya, pelayanan harus sesuai dengan kebutuhan mereka, diberikan dengan cara yang ramah pada waktu mereka berkunjung (Wijono. $\mathrm{Dj}$, 2012).

Kenyataan ini menunjukkan bahwa sikap dari petugas kesehatan itu sangat mempengaruhi terhadap puas atau tidaknya pasien dengan pelayanan perawatan yang diberikan. Sikap yang baik akan menanamkan kepercayaan pasien dengan cara menghargai, memperhatikan terhadap keluhan pasiensehingga pasien merasa diperhatikan secara manusiawi.

2) Mutu pelayanan berdasarkan ketepatan waktu

Dari hasil penelitian pada tabel 10 menunjukkan bahwa $95,7 \%$ atau hampir seluruh responden belum puas dengan 
ketepatan waktu dalam melakukan pelayanan yang ada di Puskesmas Kecamatan Lamongan. Agar berhasil, layanan kesehatan itu harus dilaksanakan dalam waktu dan cara yang tepat dan menggunakan peralatan dan obat yang tepat serta dengan biaya yang efisien (Pohan, 2012).

Kenyataan ini menunjukkan bahwa petugas kesehatan belum mampu melakukan pelayanan kesehatan dengan tepat waktu. Misalnya waktu tunggu untuk melakukan pemeriksaan yang lama. Hal ini dikarenakan terbatasnya jumlah petugas kesehatan yang ada.

3) Mutu pelayanan berdasarkan prosedur

Dari hasil penelitian pada tabel 11 menunjukkan bahwa 73,9\% atau lebih dari sebagian responden puas dengan prosedur yang dilakukan di Puskesmas Kecamatan Lamongan. Prosedur yang dilakukan oleh puskesmas menggambarkan mutu pelayanan yang diberikan oleh puskesmas tersebut. Prosedur merupakan suatu seni atau rangkaian langkah - langkah yang saling berhubungan atau pekerjaan - pekerjaan yang dinyatakan secara kronologis dengan maksud untuk mencapai maksud tertentu yang harus diikuti (Wijono. Dj, 2012).

Kenyataan ini menunjukkan bahwa petugas kesehatan sudah mampu dalam memberikan tindakan keperawatan yang sesuai dengan urutan atau langkah - langkah yang sudah ditentukan.

4) Mutu pelayanan berdasarkan sarana dan prasarana

Dari hasil penelitian pada tabel 12 menunjukkan bahwa $69,6 \%$ atau lebih dari sebagian responden belum puas dengan sarana dan prasarana yang ada di Puskesmas Kecamatan Lamongan. Sarana dan prasarana kesehatan adalah tempat yang digunakan untuk menyelenggarakan upaya kesehatan yang meliputi balai pengobatan, puskesmas, Rumah Sakit, praktek dokter, praktik bidan, laboratorium dan sarana kesehatan lainnya (Wijono. Dj, 2012).

Kenyataan ini menunjukkan bahwa dibagian tertentu dari puskesmas yang masih belum bekerja secara optimal misalnya sarana laboratorium yang peralatannya belum lengkap dan kursi untuk pasien yang menunggu giliran panggilan pemeriksaan belum tersedia dengan cukup.
5) Mutu pelayanan berdasarkan jumlah petugas

Dari hasil penelitian pada tabel 13 menunjukkan bahwa $87,0 \%$ atau hampir seluruh responden belum puas dengan jumlah petugas kesehatan yang ada di Puskesmas Kecamatan Lamongan. Kenyataan ini menunjukkan bahwa jumlah petugas kesehatan yang ada di Puskesmas Kecamatan Lamongan ini belum seimbang dengan jumlah pasien yang berkunjung ke puskesmas.

Petugas kesehatan adalah setiap orang yang mengabdikan diri dalam bidang kesehatan serta memiliki pengetahuan dan atau ketrampilan melalui pendidikan dibidang kesehatan yang untuk jenis tertentu memerlukan kewenangan untuk melakukan upaya kesehatan (Wijono. Dj, 2012). Dalam hal ini pelayanan yang bermutu dipengaruhi oleh salah satunya petugas kesehatan. Jadi harus seimbang antara jumlah petugas kesehatan dengan jumlah pasien yang berkunjung.

6) Mutu pelayanan

Dari hasil penelitian pada tabel 14 menunjukkan bahwa 73,9\% atau lebih dari sebagian responden puas dengan pelayanan yang diberikan di Puskesmas Kecamatan Lamongan. Kenyataan ini menunjukkan bahwa mutu pelayanan yang diberikan oleh Puskesmas Kecamatan Lamongan sudah optimal.

Mutu pelayanan adalah suatu keputusan yang berhubungan dengan proses pelayanan yang berdasarkan tingkat dimana pelayanan memberikan kontribusi terhadap nilai out cames (Wijono. Dj, 2012). Hal ini menunjukkan bahwa jika mutu pelayanan yang diberikan oleh puskesmas itu bermutu maka pasien akan merasa puas karena salah satu indikator mutu pelayanan adalah tingkat kepuasan pasien sebagai pengguna jasa.

\section{KESIMPULAN}

Berdasarkan penelitian diatas dan pembahasan mengenai gambaran mutu pelayanan perawatan dan tingkat kepuasan pasien di Puskesmas Kecamatan Lamongan, penulis mengambil kesimpulan sebagai berikut :

1. Lebih dari sebagian responden atau $73,9 \%$ puas terhadap mutu pelayanan 
perawatan yang diberikan Puskesmas Kecamatan Lamongan.

2. Hampir seluruh responden atau $87,0 \%$ tingkat kepuasan responden tinggi.

\section{DAFTAR PUSTAKA}

Effendy, Nasrul. 2008. Dasar-dasar Keperawatan Kesehatan Masyarakat. Jakarta. EGC.

Kementrian Kesehatan RI. 2018. Profil Kesehatan Indonesia 2017. Jakarta: Kemenkes RI.

Notoatmodjo, S. 2010. Metodologi Penelitian Kesehatan. Jakarta : Rineka Cipta.

Nursalam. 2016. Metodologi Penelitian Ilmu Keperawatan. Jakarta: Selemba Medika.

Pohan.I.S. 2012. Jaminan Mutu Layanan Kesehatan. Jakarta:Penerbit EGC.

Wijono, Dj. 2012. Manajemen Mutu Pelayanan Kesehatan: Teori, Strategi dan Aplikasi.Volume. 2. Cetakan Kedua. Surabaya. Airlangga Unniversity Press 